\title{
Value Assessment Frameworks in the United States: A Call for Patient Engagement
}

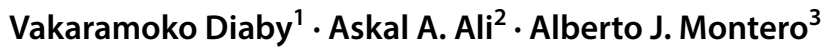

Published online: 4 September 2018

(c) The Author(s) 2018

\section{Background on Value Assessment Frameworks in the United States}

In our current environment of sustained increases in healthcare costs, evidence-based frameworks serve to inform healthcare decision-making in healthcare systems worldwide and to help control healthcare expenditures through the reduction of clinical variation. In the United States (US), decision-making regarding the evaluation of healthcare technologies was originally informed by health technology assessment (HTA) as evidenced by the creation of the Office of Technology Assessment (OTA) in 1972 [1]. Since the 1990s, healthcare expenditures in the US, as a percentage of gross domestic product (GDP) have dramatically risen compared to peer Organisation for Economic Co-operation and Development (OECD) countries, with healthcare outcomes that lag significantly behind other peer countries that spend much less. Consequently, the US has started transitioning from a volume-based healthcare system to one that focused more on "value" [2]. But what does value mean in a healthcare context? There is a lack of agreement on the meaning of value given the differing perspectives that exist

Vakaramoko Diaby

v.diaby@cop.ufl.edu

Askal A. Ali

askal.ali@famu.edu

Alberto J. Montero

MONTERO2@ccf.org

1 Pharmaceutical Outcomes and Policy (POP), College of Pharmacy, HPNP 3317, University of Florida, 1225 Center Drive, Gainesville, FL 32610, USA

2 Economic, Social and Administrative Pharmacy, College of Pharmacy and Pharmaceutical Sciences, Florida A\&M University, 200 Dyson Pharmacy Bldg., 1520 Martin Luther King Jr. Blvd, Tallahassee, FL 32307, USA

3 Department of Hematology/Oncology, Taussig Cancer Institute, Cleveland Clinic, 9500 Euclid Avenue/R35, Cleveland, OH 44195, USA (e.g., those of researchers, payers, clinicians, and patients). With rationality and asymmetric information assumptions, economists typically define value as an opportunity cost, meaning what the consumer is willing to forgo to obtain specific goods or services [3].

Value assessment frameworks have diverse applications in a healthcare setting. Some are used primarily to make coverage and reimbursement decisions, while others are used to help inform treatment decisions. As an example, from a payer perspective, the value of a pharmaceutical product indicated to treat a chronic condition relates to its ability to either avoid or reduce the number of emergency room visits and hospitalizations, thus resulting in cost savings. A clinician would value the clinical attributes of a medication (safety, efficacy, toxicity), which usually would not explicitly take into account other attributes less directly related to the clinical effectiveness of a particular medication, such as, route of treatment administration (e.g., oral, subcutaneous injection, intravenous, etc.) or patient out-of-pocket costs.

Over the last decade, we have witnessed the emergence of several value assessment frameworks that are used by different professional organizations in the US. Figure 1 shows historical events preceding the rise of these value assessment frameworks.

Professional organizations involved in the development of value assessment frameworks include the American Society of Clinical Oncology (ASCO) [5], the American Heart Association (AHA)/the American College of Cardiology (ACC) [6], the Institute for Clinical and Economic Review (ICER) [7], the Memorial Sloan Kettering Cancer Center (MSKCC) [8], and the National Comprehensive Cancer Network (NCCN) [9]. The primary purpose of these value assessment frameworks is to inform different stakeholders and to realign healthcare decision-making, based on the most robust clinical evidence, with health economic considerations such as reimbursement and coverage decisions. Understanding the potential impact that these frameworks may have on informing healthcare decision-making and their 


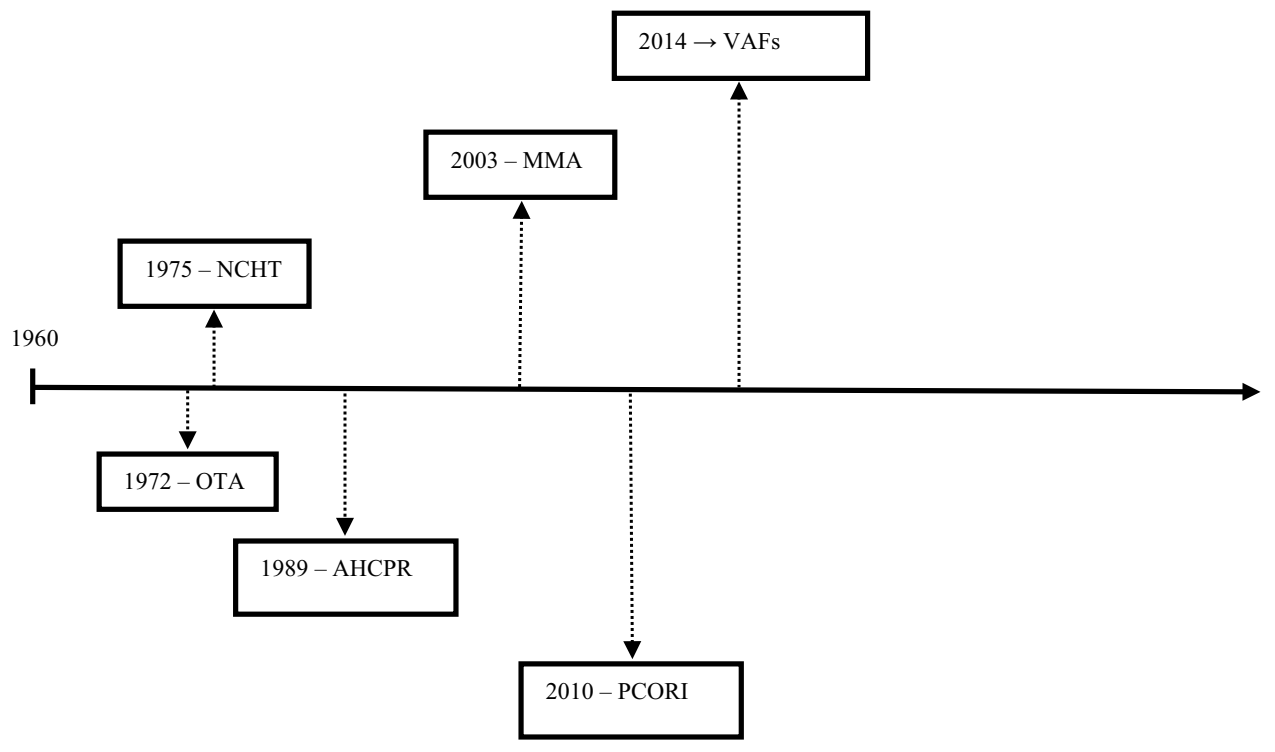

Fig. 1 Historical background of value assessment frameworks in the US. Adapted from Ali et al. [4]. OTA Office of Technology Assessment (1972) (role: assessing the effectiveness and cost-effectiveness of healthcare services), NCHT National Center for Healthcare Technologies (1975) (role: endorse research on healthcare technologies), AHCPR/AHRQ Agency for Health Care Policy and Research/Agency for Healthcare Research and Quality (1989) (role: development of

impact on reducing unwanted clinical variation and improving clinical outcomes in our healthcare system, it is essential to ensure that they do not constitute a barrier to progress against unmet medical needs [10-12].

\section{Concerns over the Implementation of Value Assessment Frameworks}

There are several legitimate concerns over widespread implementation of value assessment frameworks. First, there is a lack of consensus on assessment processes and vetting of methods used to establish value [10]. In other words, the development of frameworks should be theory and data driven and tested prior to the widespread use of value frameworks in routine clinical practice. One way to address this concern would be the establishment of guidelines for the creation and implementation of value assessment frameworks, thereby ensuring that frameworks serve the aims of improved clinical outcomes, controlling healthcare costs, and patient preference. A second common concern about the implementation of value assessment frameworks is the absence of transparency in the way they synthesize clinical evidence to arrive at their recommendations. Value assessments of health technologies (HTs) are inherently complex and multifaceted, and these assessments inconsistently apply criteria and involve implicit judgments [13]. As a result, evidence and clinical practice guideline), $M M A$ Medicare Prescription Drug, Improvement, and Modernization Act (2003) (role: list of required research to demonstrate the outcomes, comparative clinical effectiveness, and appropriateness of healthcare items and services), PCORI Patient-Centered Outcome Research Institute (2010) (role: fund comparative effectiveness research), VAFs value assessment frameworks (2014-present)

more evidence-based, reproducible, and transparent frameworks are needed. One avenue to address this issue would be the formal consideration of multi-criteria decision analysis [14] to facilitate transparent aggregation of evidence and preferences as part of value assessment processes [13, 15]. A third concern is the absence of the patient perspective. Very few value assessment frameworks explicitly account for the patient perspective by including decision-making attributes that matter most to them, such as treatment modality (mode of administration) and schedule (visit frequency) [16], or reduction on the burden on caregivers [10]. These attributes go beyond traditional value assessment criteria, and their relative weights may vary greatly between patients.

\section{A Call for Patient Engagement}

Given the ongoing concerns about rapidly rising healthcare costs and the realization that a paradigm change from volume to value is needed, value assessment frameworks will likely have a more prominent role in which healthcare interventions are adopted by healthcare providers, payers, and ultimately patients. From a societal perspective, if patientcenteredness is truly a core value, as scientific advances permit greater treatment personalization of complex diseases such as cancer, it is critical that value assessment frameworks strike a balance between decision-making at 
population and individual levels. No matter what perspective is adopted by value assessment frameworks, patients should still remain at the center. This reinforces the need to ensure that healthcare value assessment frameworks are rigorously developed and result in robust, consistent, and transparent information through the development of best practices to guide the development and implementation of these frameworks. Research is warranted for the testing and validation of methods that are used in value assessment frameworks. This call for research on value assessment frameworks is coupled with a call for increased funding opportunities to support these research efforts. It is reassuring to see that the Pharmaceutical Research and Manufacturers of America (PhRMA) foundation is leading the way by supporting research, through the foundation's value assessment initiative (VAI), that would address "issues in methodology and patient engagement" [17].

Acknowledgements We thank Tim Wrightson, Co-Editor of PharmacoEconomics - Open, for his comments and suggestions on earlier drafts of this editorial. We also thank Kyrian Ezendu, a Ph.D. candidate in the Division of Economic, Social and Administrative Pharmacy, College of Pharmacy and Pharmaceutical Sciences, Florida A\&M University, for his assistance with the literature search.

\section{Compliance with Ethical Standards}

Funding No funding was received for the writing of this editorial.

Conflict of interest Vakaramoko Diaby, Askal A. Ali and Alberto J. Montero have no conflicts of interest to declare.

Open Access This article is distributed under the terms of the Creative Commons Attribution-NonCommercial 4.0 International License (http://creativecommons.org/licenses/by-nc/4.0/), which permits any noncommercial use, distribution, and reproduction in any medium, provided you give appropriate credit to the original author(s) and the source, provide a link to the Creative Commons license, and indicate if changes were made.

\section{References}

1. Marko NF, Weil RJ. An introduction to comparative effectiveness research. Neurosurgery. 2011;70(2):425-34.

2. Burwell SM. Setting value-based payment goals-HHS efforts to improve U.S. health care. N Engl J Med. 2015;372(10):897-9.
3. Garrison LP, Neumann PJ, Willke RJ, et al. A health economics approach to US value assessment frameworks-summary and recommendations of the ISPOR special task force report [7]. Value Health. 2018;21(2):161-5.

4. Ali AA, Xiao H, Campbell ES, Diaby V. Improving health care decision making in the USA through comparative effectiveness research: the role of economic evaluation. Pharm Med. 2015;29(5):247-53.

5. Schnipper LE, Davidson NE, Wollins DS, et al. Updating the American Society of Clinical Oncology value framework: revisions and reflections in response to comments received. J Clin Oncol. 2016;34(24):2925-34.

6. Anderson JL, Heidenreich PA, Barnett PG, et al. ACC/AHA statement on cost/value methodology in clinical practice guidelines and performance measures: a report of the American College of Cardiology/American Heart Association task force on performance measures and task force on practice guidelines. J Am Coll Cardiol. 2014;63(21):2304-22.

7. Institute for Clinical and Economic Research. Overview of the ICER value assessment framework and update for 2017-2019 (2017). https://icer-review.org/methodology/icers-methods/icervalue-assessment-framework/. Accessed 15 July 2018.

8. Memorial Sloan Kettering Cancer Center. Drug abacus FAQs. http://www.drugabacus.org/faqs. Accessed 15 July 2018.

9. National Comprehensive Cancer Network. NCCN clinical practice guidelines in oncology (NCCN guidelines) with NCCN evidence blocks $^{\mathrm{TM}}$. http://www.nccn.org/evidenceblocks. Accessed 15 July 2018.

10. Leonard D. Guiding practices for patient-centered value assessment. Am J Pharm Benefits. 2017;9(5):160-1.

11. Westrich K. Current landscape: value assessment frameworks. Washington, DC: National Pharmaceutical Council; 2016.

12. Westrich K, Buelt L, Dubois RW. Why value framework assessments arrive at different conclusions: a multiple myeloma case study. J Manag Care Spec Pharm. 2017;23(6-a Suppl):S28-33.

13. Diaby V, Goeree R, Hoch J, Siebert U. Multi-criteria decision analysis for health technology assessment in Canada: insights from an expert panel discussion. Expert Rev Pharmacoecon Outcomes Res. 2015;15(1):13-9.

14. Belton V, Stewart T. Multiple criteria decision analysis: an integrated approach. New York: Springer Science and Business Media; 2002.

15. Diaby V, Campbell K, Goeree R. Multi-criteria decision analysis (MCDA) in health care: a bibliometric analysis. Oper Res Health Care. 2013;2(1-2):20-4.

16. Havrilesky LJ, Alvarez Secord A, Ehrisman JA, et al. Patient preferences in advanced or recurrent ovarian cancer. Cancer. 2014;120(23):3651-9.

17. Pharma Foundation. Value assessment: improving patient outcomes and reducing inefficiency. http://www.phrmafoundation .org/2018-awards/value-assessment-initiative/. Accessed 20 Aug 2018 . 